\title{
RE-CONCEPTUALIZING L2 WRITING REVISION STRATEGIES FROM AN ECOLOGICAL PERSPECTIVE: AN INTERVIEW BASED INQUIRY
}

\author{
Masakazu Mishima \\ Rikkyo University, Japan \\ E-mail: mmishima@rikkyo.ac.jp
}

APA Citation: Mishima, M. (2019). Re-conceptualizing L2 writing revision strategies from an ecological perspective: An interview based inquiry. English Review: Journal of English Education, 7(2), 1-16. doi: 10.25134/erjee.v7i2.1771.

\begin{abstract}
This study examines an ESL writer's revision activity in composing an argumentative essay from an ecological perspective. The study aimed to explore how sociomaterial conditions present in the pedagogical context lead to the writer's use of revision strategies in responding to instructor feedback. By using an interview-based case study approach, data were collected from one ESL writer and instructor in an ESL freshman composition class at a large public university in the US. Based on the analysis of field-notes, transcripts from interviews and writing conferences, and various cultural artifacts, the study found that the writer's goal-oriented agency foregrounded his engagement with instructor feedback, which narrowed down the problem space perceived to be important by the writer to achieve his goal in writing. The writer's selective attention to the specific writing issues to be attended in his revision attempt provided an essential perceptual pretext for the concoctions of several sociomaterially-afforded revision strategies. The study also found that sociomaterial interactions inherent within one strategy use conditioned the emergence of another strategy while showcasing that the writer's strategy use could be emergent and generative in nature. Based on the findings, the study discusses the emergence of the revision strategies as a result of collective interplay of student agency and student-perceived sociomaterial affordances in the writer's attempt to establish sociocognitive alignment with the instructor's expectations delivered through feedback. Implications for ecologically-oriented L2 revision strategy research are discussed.
\end{abstract}

Keywords: ecological approach; L2 revision strategies; L2 writing feedback; L2 writing process.

\section{INTRODUCTION}

As we view writing as fundamentally a social act, the immediacy to examine L2 writing process as a socially situated activity naturally emerges; it requires accounts of the very context in which L2 writers engage in writing activity. In concert with the socially situated view of writing, the importance of contextual matters in L2 writing research has been increasingly recognized (Casanave, 2003; Ferris, 2014; Hyland \& Hyland, 2006; Lee, 2008; Lei, 2008). This largely sociocultural movement has led researchers to expand the scope of analysis deeply into social aspects of writing as opposed to cognitioncentral views of writing (see for partial review, Leki, Cumming, \& Silva, 2008; Cumming, 2001). The movement signifies a response to an increasing call for context-sensitive research on L2 writing to move away from a componential analysis of the apparently complex nature of L2 writing. The resultant effort is now visible in an increasing number of L2 writing studies with an utmost focus on social interactions as prominently capitalized in sociocultural framework of investigations (e.g., De Guerrero \& Villamil, 1994; Han \& Hyland, 2016).

Although the increasing attention to the matters of context is a welcoming trend, an exclusive focus on social interactions does not do justice in an attempt to explain an individual's act of writing, which occurs in tandem with both social and material interactions. Accordingly, an investigation into L2 writing process requires an integrative perspective, which Nishino and Atkinson (2015) succinctly referred to as, "a rich ecology of mind, body, and sociomaterial world" (p. 38).

In light of this ecological notion above, it appears that the current landscape of L2 writing process research is limited in providing accounts of how students engage in writing in direct response to instructor feedback with which and for which the individual establishes unique relationships, while interacting with various temporal sociomaterial conditions present in his/her learning environment. The present research hence was conducted as an exploratory attempt to capture one aspect of L2 writing 
process-an L2 writer's use of revision strategies-as deeply situated in a specific pedagogical ecology wherein instructor feedback and other sociomaterial resources play a key role in directing the student's revision attempts. To set a stage for the present research, the following reviews select studies from L2 writing strategy research.

\section{L2 writing strategy research}

L2 writing strategy research has been receiving significant attention from researchers in conjunction with the widespread practice of the process-writing approach since 1970s (Reid, 2001; Silva, 1990). In the process-approach, writers go through a series of stages in the act of composing texts, such as planning, drafting, revising, and editing (Seow, 2002), and at any stage of writing, writers may use strategies/approaches to facilitate their acts of writing (Manchon, Roca de Larios, \& Murphy, 2007). Since the process of writing is intimately associated with individual acts of writing including strategy use, L2 writing scholars have been actively investigating writers' strategy use (Bosher, 1998; Hedgcock, \& Lefkowitz, 1992; Leki, 1995; Raimes, 1985, 1987; Roca de Larios, Murphy, \& Manchon, 1999; Sasaki, 2000, 2002).

Early studies in L2 writing strategy were predominantly cognitive in nature and focused on exploring mental processes and strategies used by student writers (Oxford, 1990; Wenden \& Rubin, 1987; Zamel, 1983). These early studies prototypically characterized learners' strategy use as a problem-solving device with the underlying assumption of text-mind dualism.

In the late 90s and onward, L2 writing strategy research focused on identifying factors which may have bearing on L2 writers' strategy use. This line of research identified a number of factors leading to individual differences in strategy use. For instance, researchers reported ESL writers used different revision strategies depending on the nature of writing issues they faced (Conrad \& Goldstein, 1999; Hyland, 1998; Yasuda, 2004, 2005; Wong, 2005). Sze (2002) and Wong (2005) showed that L2 writers' strategy use changed from one stage of drafting to the next. Takagaki (2003) specifically examined the strategy use of L2 writers at a revision stage and found that their strategy use was positively related to knowledge of revision task including their prior writing experience.

More recent studies on L2 writing strategy became increasingly situated in nature by paying more focused attention to sociomaterial resources and their roles in L2 writers' strategy use. In particular, researchers have been attempting to explore how L2 writers use their strategies by capitalizing on the notion of mediated-actions from a sociocultural perspective. Lei (2008), for example, used a sociocultural framework to investigate L2 writers' strategy use in relation to various tools in the specific L2 writing environment. The study demonstrated the L2 writers' strategy use was mediated through a variety of social and material resources.

Another example of socially and materially mediated L2 writers' strategy use was reported in Bhowmik (2016). The study specifically addressed the role of agency, identity, and ideology in L2 writers' strategy use and it identified the writers' agency played a significant role in accounting for differences in their strategy use. In addition, the writers' identity and ideology manifested as values, beliefs, assumptions, and perceptions of writing tasks which collectively fed into their highly deliberate and purposeful selections of strategy use.

Lei (2008) and Bhowmik's (2016) studies were exemplary in the respect that both of them captured L2 writing strategies as deeply immersed in a sociocultural context of writing wherein the writer as a whole person interacts with the environmental resources (i.e., social and/or material) and make agentive and ideological decisions in the process of writing. However, neither of the studies above considered instructor feedback as part of their investigations despite its well-recognized role as an important pedagogical intervention in the process-writing classroom. Furthermore, currently available L2 writing strategy research is insufficient in explaining how an L2 writer selects socially and/or materially mediated strategies in the process of writing, most particularly in relation to student agency and temporal contextual conditions surrounding L2 writers. Lei (2008) thus far pointed out the need for future research to probe deeply into the local and historical contexts of individual writing activities in order to further our understanding of how L2 writers select to use different L2 writing strategies.

An overview of the previous studies reveals the scarcity of accounts as to how L2 writers determine to use specific sociomaterial tools to mediate their acts of writing. It is also important to note that the absence of instructor feedback in 
examining L2 writers' strategy use as in the previous studies may lack ecological validityrelevancy to the widely practiced process writing approach in L2 writing classrooms. To address the gap, the present study was conducted in a naturalistic process writing classroom wherein instructor feedback (i.e., oral and written) was periodically provided to student writers. Thereby, the researcher attempted to explore processes leading to the emergence of L2 writing strategies in response to instructor feedback and their underlying contextual conditions.

\section{The ecological approach}

Although the ecological approach was originally developed in the field of biology, an American psychologist, Gibson (1979) applied the approach to study visual perception and its relationship with the environment. Later, an attempt was made by researchers to adapt it to applied linguistics research in order to use it as a metaphorical bridge to explain language learning as an environmentally situated and emergent behavior (Gee, 2004; Leather \& van Dam, 2003; van Lier, 2000, 2004, 2010).

The essential premise of the ecological approach in applied linguistics is its central focus on ecological relationships between learners and their environment (see Kramsch, 2002). It highlights that language development is in and part of the context in which it occurs. Van Lier (2010) further provides a useful summary of the ecological approach as adapted to applied linguistics:

An ecological approach aims to look at the learning process, the actions and activities of teachers and learners, the multilayered nature of interaction and language use, in all their complexity and as a network of interdependencies among all the elements in the setting, not only at the social level, but also at the physical and symbolic level. (p. 3)

As presented above, the ecological approach is characterized by its comprehensive treatment of context extending to not only learners but to teachers and their interaction at the social, physical, and symbolic level. It also denotes the inseparable link between individuals and their ecosocial environment. The ecological approach, however, is not a uniform theory, rather it is a specific way of thinking about and viewing the world, which shares similar worldviews with sociocultural theory (Lantolf, 2000) and sociocognitive approach (Atkinson, 2011; Nishino \& Atkinson, 2015).

The present research used the ecological approach to represent the researcher's overarching orientation within the conduct of the current investigation. As mentioned above, however, the ecological approach is a theoretical worldview, which is not readily applicable to empirical investigations for its broad theorization of language teaching and learning. Hence, the researcher capitalized on select conceptual tools from the aforementioned two ecologically-oriented theories to help interpret and present the findings. The adoption and adaptation of the ecological conceptual tools were carried out post-hoc in order to avoid situating the study from the top-down in a singleunified theoretical framework (e.g., sociocultural theory). Rather, the researcher conducted the study from the bottom-up (Atkinson \& Sohn, 2013). What follows is a brief overview of the key conceptual tools adopted from the two ecological theories-sociocultural theory and sociocognitive approach.

Agency. The notion of agency has been recognized as an important theoretical concept in L2 learning (Duff, 2012, Kinginger, 2004, Lantolf \& Pavlenko, 2001; Pavlenko \& Lantolf, 2000). In contrast to the traditional conceptualization of learners as passive recipients of information in the process of learning, sociocultural theorists view learners as active participants (i.e., agents), who are aware of their own capacity, reflect on their past experiences and various social conditions (e.g., classroom learning situations), and self-regulate their own learning (Lantolf \& Pavlenko, 2001).

As in any human activity, agency is a drive to move people to act in a specific manner as a person perceives it as important and necessary (Lantolf \& Pavlenko, 2001; van Lier, 2004). While agency is associated with many psychological constructs, such as motivation (Brown, 2014), a major distinctive characteristic of agency is that it includes one's perception of a goal in activity and how to achieve the goal by selecting potential actions to take (Duff, 2012). Agency thus serves as a pretext to a personalized way in which people engage in activity.

Agency, however, does not appear in isolation from the world in which people live, including social and material settings (Norton \& Toohey, 2011). Thus, it is not an exclusive personal attribute of an individual, but a sociomaterially and sociohistorically constructed 
temporal state which is always in constant motion and retains possibility for change or transformation. As we recognize the need to act and for what purpose, agency emerges and shapes the ways we act by looking around resources or affordances that can help them to act on and with the world in order to achieve the goal (Bhowmik, 2016). In a similar vein, van Lier (2008) views agency as person-in-context"an awareness of the responsibility for one's own actions vis-à-vis the environment, including affected others" (p. 17). Agency in this way permeates our actions as it regulates our actions and gives us the directions to the action or activity. Accordingly, agency has to be present when learning, including learning to write.

In the present research, the researcher adopted an ecosocially situated view of agency as presented above for its compatibility with the ecological approach and overall conceptual fitness to present the findings of the current study. In more specific terms, the concept of agency is used to show how the writer-perceived goal of writing gives rise to agentive engagement in one L2 writer's revision activity and how it uniquely shaped the ways in which he attempted to revise his essay draft.

Alignment. The notion of alignment has been predominantly used in research on interpersonal interactions though from different orientations (see Atkison, Churchill, Nishino, \& Okada, 2007; Nishino \& Atkinson, 2015; Costa, Pickering, \& Sorace, 2008; Garrod \& Pickering, 2009). The present research adopted the alignment principle of the sociocognitive approach proposed and incorporated into L2 writing research (Nishino \& Atkinson, 2015). In the sociocognitive approach, the alignment principle denotes "the complex means by which human beings effect coordinated interaction, and maintain that interaction in dynamically adaptive ways" (Atkinson, et al., 2007, p. 169). In this principle, human behaviors are always in the process of achieving harmony with both social and material environments by means of adaptation, as Nishino and Atkinson (2015) stated, "we would simply add that social relationships are always also ecosocial relationships-individuals act in, on and in concert with their non-human environments in order to adaptively survive in them" (p. 39).

Alignment is also relevant to agency and is viewed as a form of learning (Wang \& Wang, 2014). If agency gives a volitional direction within the confinements of sociomaterial conditions including potential environmental resources and the norms or rules of conduct within a community/classroom to social activity (e.g., writing), then alignment refers to the processes in which the agent adaptively attempts to minimize the distance between what the agent already knows and needs to learn through sociomaterial interactions.

In keeping with the sociocognitive notion of alignment above, the researcher views alignment as an intermediary adaptive and agentive process of learning through sociomaterial interactions, and also a temporal state of that process, which subsumes the object of the current investigation-revision process. In particular, the study presents what the L2 writer attempted to establish alignment with in the course of his revision activity and how it contributed to the writer's engagement with instructor feedback.

Affordance. The concept of affordance refers to potential mediating tools for taking action (Gibson, 1979). For a potential tool to mediate action, one needs to perceive the existence of the tool, relevancy of it to the activity, and how to use the tool to facilitate the activity. This point is highlighted in Gibson (1979) and Gibson and Pick (2000) in differential theory of perception. The environment offers overwhelmingly rich tools for us to manipulate and coordinate our actions (van Lier, 2004). However, due to the limited capacity of our sensory systems and cognition, not every potential tool is perceived and used as a mediating tool. Therefore, we naturally pay selective attention to potential mediating tools or affordances in relation to a given activity and the goal of the activity. Hence, our perceptions need to be differentiated between what to perceive and not to perceive.

The directions of our attention are tightly intertwined with our personal exigency or agency to act as Gibson (1982) viewed, "we do not perceive stimuli or retinal images or sensations or even just things; what we perceive are things that we can eat, or write with, or sit down on, or talk to" (p. 60). Agency guides the ways we act and thus it also encompasses what we perceive to be an affordance including its relevancy to the activity. Therefore, the primary locus of affordance is identified in a relationship between the individual unique agency and social as well as material others. Furthermore, agents' physical and/or social engagement with potential tools must necessarily present as priori in mediated actions. This essentially means that an 
agent must first establish some level of connection or attempt to be in alignment with potential affordances in the ecosocial environment.

In summation, the way in which an individual perceives and uses affordances is intimately associated with his/her agency and the level of alignment with the environment. Thus, any affordance-mediated action or activity including act of revising is enacted through one's agency and the nature of alignment in and with the environment.

The concept of affordance above is used in the current investigation to present the specific sociomaterial tools which mediated the L2 writer's revision activity and how they contributed to the emergence of sociomaterially conditioned revision strategies in conjunction with the writer's agency and alignment with sociomaterial tools.

\section{METHOD}

The present research aimed to analyze; 1) the revision strategies used by an L2 writer in response to instructor feedback, 2) the sociomaterial resources used in the identified revision strategies, and 3) how the identified revision strategies emerge in the process of an L2 writer's revision activity. This study was conducted at a large public university with one of the highest concentrations of international students in the US. The university offers an ESL version of freshman composition course designed specifically for nonnative English speaking students. Data were collected from a section of the aforementioned composition course during which students engaged in a threeweek long argumentative essay writing assignment. In the first week of the writing assignment, students received assignment directions, lectures, and engaged in practice activities to be ready to take on the assignment. In the second and third week, each student was required to meet their instructor in a 15 minute one-on-one writing conference. The writing conference session was held once a week for each student and lasted for two weeks before the submission of final drafts. At each conference session, the instructor returned a student's essay draft with written feedback and discussed his/her writing.

This study involved one instructor and one L2 writer in a section of the ESL freshman composition course. Prior to data collection, both participants received a research invitation with descriptions of the research and tasks to be completed. Upon consent, the researcher observed all lectures, classroom activities, and writing conferences for three weeks during which students worked on the argumentative essay writing assignment.

The Instructor, Elif, was a 34-year-old female from Turkey. At the time of the research, she was a Ph.D. student at the university majoring in Second Language Studies. While she had no prior educational background related to teaching composition, she received threesemester long in-service training and was already an experienced composition instructorone year teaching experience in mainstream freshman composition classes and three additional years of teaching ESL composition.

The Student, Jiang, was a 20-year-old male from an urban city in China. He was a sophomore student at the university majoring in Economics. Although he came to the university at the beginning of his sophomore year, he was placed in the ESL freshman composition class since it was a required course for graduation. After his undergraduate studies, he was planning to go back to China and work for his father's company. As for his experience in L2 writing, he reported that he had never experienced writing in the process-oriented classroom or received any form of feedback from his instructors in China.

The study initially used a situated case study approach (Atkinson, 2005). In particular, the study capitalized on student interview data which contained the detailed accounts of Jiang's strategy use. In addition, the researcher collected a wide array of cultural artifacts to better contextualize his revision activity. The sample size was intentionally kept minimal to allow for an in-depth analysis of one student writer's revision activity. The method adopted is epistemologically interpretivist in nature (see Denzen \& Lincoln, 2011). Therefore, the study does not seek to generalize its findings but rather particularize them.

During the entire course of data collection, the researcher assumed the role of observerparticipant whose involvement in the field was strictly maintained as an observer by minimizing any interactions with the members of the social setting (Gold, 1958). Data sources collected and analyzed in the present research were: (a) field notes, (b) recording transcripts from lectures and student-instructor writing conferences, (c) student and instructor interview transcripts, and 
(e) cultural artifacts (e.g., classroom materials and essay drafts).

In order to ensure the systematic data collection and analysis of multiple data sources, the researcher used several techniques widely adopted in qualitative research, such as theoretical sampling, constant comparison, member checking, open-coding, and triangulation (see for review, Yin, 2014). The techniques were used as an integral part of data collection and analysis. Thus, data collection and analysis were simultaneous processes of the entire research conduct. This is a common procedure especially in situated qualitative research wherein researchers exercise constant reflexivity, which is by large a non-linear process (Atkinson, 2005).

After the formal data collection period was over, the researcher continued to analyze the data gathered to identify common threads cutting across all data sources and generate final research narratives. The details of data collection and analysis procedures for each data source are presented in the following sections.

Field notes. Field notes were produced based on classroom and conference observations. The researcher took detailed notes of classroom activities and writing conferences. In addition, all observed classroom activities and writing conferences were recorded by a voice-recorder and subsequently transcribed to add any missing information to the field notes. These notes were coded to classify them into thematic categories with associated descriptors. The coded notes were constantly revised as new data were entered into analysis. Once the emerged codes were finalized, they were used to produce the descriptions of the instructional context specifically of lecture topics, the writing assignment, and student-instructor interpersonal interactions during writing conferences to facilitate the analysis and interpretation of Jiang's accounts of his strategy use.

Interview transcripts. The researcher conducted a total of three interviews individually with the instructor and student for 30 minutes to one hour per session. Interview questions were semi-structured; there were several prestructured questions which were prepared based on the field notes and directed at the participants to clarify and/or confirm the information (i.e., member checking) obtained from classroom and conference observations. During one of the interview sessions with the student participant, a stimulated recall task was conducted by using the instructor-commented first and second drafts of Jiang's argumentative essay to probe into his revision strategies. All interview data were transcribed for analysis. Then, the transcribed interview data were coded to find common threads and organize the data accordingly to the thematic categories emerged. Similar to field notes, the emerged codes and their associated descriptors were constantly revised and compared with the themes identified in the other data sources.

Cultural artifacts. The researcher collected all materials produced and/or used by the participants in the field, including course syllabus, class schedule sheet, assignment sheet, lecture slides, worksheets, instructor-commented argumentative essay drafts, and eight sample essays. These cultural artifacts were thematically organized and then used to gain an insight into the pedagogical intentions/expectations of the instructor in relation to the argumentative essay writing assignment. The sources were then used to help interpret Jiang's revision strategy use.

Data integration and production of research narratives. In the entire process of the data collection and analysis presented above, the researcher produced reflective research notes or more formally knowns as memos (Glaser, 1978), which contains various interpretations of the thematic categories and descriptors emerged from each of the data sources. At the final stage of analysis, the researcher further compared coded data with their associated descriptors and memos across all data sources to identify similarities, differences, and relationships. In this process, the researcher refined the memos in an attempt to produce research narratives in relation to the purpose of the research. This process was by its nature, involved a higher level of interpretation-an analytical shift from a predominantly emic to increasingly etic perspective to situate the study in relation to the researcher's positionality - the ecological approach. It involved an active attempt to search conceptual tools in producing locally situated narratives or meta-narratives without forcing the data (Lyotard, 1984). The researcher adopted three major conceptual tools related to the ecological approach presented earlier-agency, alignment, and affordance - to produce the research narratives and present the findings.

\section{RESULTS AND DISCUSSION}

Results are presented in five sections to demonstrate how the student writer's agentive 
engagement emerged and how his several revision strategies were intimately associated with the sociomaterial resources available in his perceived environment. As mentioned earlier, the results that follow are primarily based on Jiang's accounts of revision strategy use while contextualizing them where relevant via the other data sources.

\section{Jiang's agency: The goal of writing}

During the first interview with Jiang, he described at some length his goal of writing and how to achieve the goal which seems to have foregrounded his agency-the desire to align with Elif's pedagogical expectations delivered through her feedback:

\section{Excerpt \#1}

Researcher : What is the goal of writing for you, Jiang?

Jiang : What do you mean?

Researcher : I mean, you are learning to write, right [in Elif's class]? Do you want to improve your writing skills?

Jiang : To be honest, I don't care about English writing. But it's a required course so I have to do it.

Researcher : Would you take the course if not required?

Jiang : No way. Elif's class is very very hard and I don't need to write once I go back to China.

Researcher : What is your plan after you return to China?

Jiang : I [will] work for my father's company. And I don't need to write in English.

Researcher : So then what motivates you to write?

Jiang : I want to get a good grade. I have to write a good paper so I can get a good grade. I try hard to understand what Elif wants me to do.

Researcher : Why do you try so hard to understand what Elif wants?

Jiang : Hmm...she is the instructor. You need to do what the instructor says to get a good grade.

Researcher : Does Elif's feedback help you understand what she wants?

Jiang : It's difficult sometimes but I read feedback carefully and ask questions when I see her [at a writing conference].

Researcher : Is that how you studied in China? Or something that you do in Elif's class?

Jiang : I always listened to what the teacher says in China and I can get a good grade. I just do it the same way [in Elif's class].

As the excerpt shows, Jiang's goal of writing - to receive a good grade and his belief about how to achieve the goal are the prominent sources of his agency. In particular, Jiang's agency manifested as the need to align with Elif's pedagogical expectations/intentions expressed through feedback to ensure a good grade as he stated, "you need to do what the instructor says" or "I read feedback carefully and ask questions..." Jiang's agency is also a product of his past successful learning experience in China, "I always listened to what the teacher says in China and I can get a good grade." His goal-oriented agency above was an important source of drive which appeared to have shaped the nature of Jiang's engagement with instructor feedback and the emergence of his revision strategies as presented in the following sections.

\section{Strategy to align with the instructor's expectations}

The excerpts below exemplify Jiang's active agentive attempt to align with the instructor's pedagogical intentions communicated through written feedback, and thereby to produce a revised essay that satisfies the instructor so as to receive a good grade. During the stimulated recall task at the third interview session, Jiang compared the first and second drafts and attempted to recall how he revised his first draft. Jiang reported that he tracked all feedback instances from the top of the paper to the bottom to not to miss out on any feedback. This strategy of responding to instructor written feedback can be called the head-to-toe approach in my own terms.

\section{Excerpt \#2}

Jiang : I look at all the comments from top to bottom. I go back to the first comment and changed the title. Then, I forgot to put page numbers so I added them.

I worked on the first argument, added more reason to it and revised the thesis statement. In the same way, I looked at all the other comments and made changes.

Jiang's brief report above indicates that he attempted to revise his draft, while attending to all instances of Elif's feedback. Jiang's exclusive focus on Elif's feedback was further confirmed as he elaborated his head to toe approach:

\section{Excerpt \#3}

Jiang : I always retype everything. I look at comments and type everything [on a new Word document] for second or 


\section{Masakazu Mishima}

third draft. In this way, I can check all the comments and find mistakes that I missed.

Researcher : When you write in Chinese, do you do this?

Jiang : No.

Researcher : So only when you write in English then?

Jiang : Yes. I have never done this before this class.

Researcher : You mean, you do it only for Elif's class? Do you do this in your other classes?

Jiang : No. I don't have to. I don't get feedback like this and I don't have to revise.

In the excerpt above, he explained that he had retyped his essay from scratch on a new Word document rather than making revisions to the existing draft. In this way, his retyping strategy helped him to identify any issues that he might have missed otherwise, but also to make sure to fully attend to Elif's feedback. As his head to toe approach manifested as a means to satisfy his agentive need, the retyping strategy appeared to have been used as a means to further strengthen his alignment with the instructor by faithfully following the instructor's directives.

The use of the retyping strategy was most certainly not a pure cognitive event as Jiang's retyping strategy was made possible through two specific sociomaterial tools. One is a physical copy of the instructor-commented first draft, which he received at his first writing conference and the other is his bulky silver laptop which he would always carry around in his backpack to do school assignments and/or play videogames. His alignment with those sociomaterial tools seemed to be extant as priori as indicated in the following excerpt:

\section{Excerpt \#4}

Researcher : So how did you come to use this approach[the retyping strategy]?

Jiang : I want to understand what Elif wants. So I don't want to miss any comments [Elif's feedback].

Researcher : Yeah, I get that, but you said, you retype your essay after you receive feedback, right? When did you start doing this?

Jiang : I don't remember exactly but Elif always gives me my essay when I meet her and I always do my assignments with my laptop. So I carry it in my backpack. So I have a copy of my essay and my laptop to check Elif's feedback. It became like a hmm..habit?
Researcher : How often do you use your laptop to do your assignments?

Jiang : I don't know but I have to use it almost everyday for all my classes. Also, I like playing videogames so even when I don't have assignments, I carry it anyway.

Researcher : Oh, I like videogames, too. What do you play?

Jiang : Starcraft.

Researcher : That one is very popular.

\section{Strategy to align with the instructor's unclear expectations}

Jiang's strategy use presented earlier was primarily geared toward effectively attending to Elif's feedback. However, there were some feedback instances which Jiang found difficult to respond. The difficulty stemmed from Elif's feedback which focused on Jing's writing issues related to argumentation. In particular, issues related to thesis statement (i.e., a core argumentative statement) and Jiang's use of supporting evidence are some of the major concerns expressed by Elif's written and oral feedback. Consider the excerpt below from the first writing conference with Jiang where he discussed his first draft:

\section{Excerpt \#5}

Elif : As far as I can see there are two sources-one is mental health, the other is physical health. You used sources from your interview [the previously assigned interview-based paper]. You need five written sources where you can get evidence from. They should come from research papers. What you did was turning your interview into evidence. And APA style here. This is from a book but then you have to use APA to indicate it.

Jiang : So I need to find the source and use the source to support it.

Elif : Your arguments are sound but you need to find sources, academic sources. It's just you need to provide evidence. Now, your thesis statement. I don't see you reasons. This is my stance because...I want to see your reasons here.

Jiang : You want me to give reasons so I can say my personal experiences [from the interviewbased paper]?

Elif : No, don't tell your personal story. This is your reason. It's your opinion so you don't have to provide evidence here.

Jiang : I have no more questions.

Elif : You need to work on in-text citations. For the second draft, please cite properly. There are some clarity issues. Sometimes, I don't understand. 
After the writing conference, Jiang reported to me that the issues pointed out by Elif were extremely challenging to resolve as she did not explain how or why the issues had to be resolved. Be noted that Elif's general feedback approach was to not to provide straightforward answers to the issues at hand to push students to exercise critical thinking skills and curve out their own learning paths.

\section{Excerpt \#6}

Researcher : What is your approach to providing [written] feedback?

Elif : My focus is on more global things. Do they have a thesis statement? Is the introduction good enough? Do they use transitional phrases? So I give much less feedback on grammar. I don't give comments to everything. I just underline to have students to correct themselves.

A review of Elif's written feedback shows, her feedback on global issues was predominantly provided in indirect form-underline or short verbal comment to indicate there is an issue to be attended. Elif was also inclined to use indirect feedback during the oral writing conference as in Excerpt \#5, to not to give explicit solutions (i.e., direct feedback) to Jiang's writing issues. Due to the absence of an explicit delivery of the instructor's expectations, Jiang was initially left out without a means to initiate revisions to those issues. $\mathrm{He}$, however, attempted to find a way to further strengthen his alignment with the instructor by seeking help from some of his classmates with whom he had established a rapport over the course of the semester. Consider the following excerpt:

\section{Excerpt \#7}

Researcher : I hear a lot of Chinese in class. What do you talk about in class in Chinese?

Jiang : Sometimes, we talk about assignments but sometimes we talk about something else like having dinner together or going out to a party.

Researcher : Do you ask your classmates for help with the current assignment [argumentative essay writing]?

Jiang : Yeah, I sometimes ask my friends to show me their papers. Their papers are good and they got good grades [on the previous assignments]. It helps me when I revise my arguments.

Researcher : You often sit alone in the classroom. Do you have many friends in your class?
Jiang : Not many but I know a few and their papers are good. So I talk to them when I have a problem [with assignments].

Researcher : How did your friends' papers help you to revise?

Jiang : What do you mean?

Researcher : I mean...what kind of change did you make to your draft after looking at your friends' papers?

Jiang : I looked at their thesis statements and how they used evidence. Then, I revised my thesis statement. I also asked them to share how they wrote them [their thesis statements]. They told me they checked the sample essays so I decided to look at them.

The excerpt above shows this particular strategy, which I call peer support, was used to find clues as to how thesis statement and evidence had to be presented. Jiang's purposeful selections of whom to ask for help and for what purpose were clearly evident in his report. Compared to the retyping strategy, the emergence of the peer support strategy was conditioned by the social relationship which he already had established with the select classmates, whose grades were good. I might further add that the development of this particular social relationship may be related to the demographic condition of the class which consisted of entirely Chinese. Jiang including all other students in class would often speak in Chinese during lectures and/or classroom activities. The fact that all students in this class were Chinese and spoke the same L1 may have provided an optimal condition for Jiang to develop a kind of rapport that can benefit him in completing his revision task. In this sense, Jiang's strategy use is intimately associated with the demographic characteristic of the class-a part of the pedagogical environment.

\section{Interaction between strategies}

When using the peer support strategy, Jiang identified one other outlet to respond to Elif's indirect feedback. In his interaction with the peers presented earlier, he became aware of the sample essays which Elif posted to Blackboard, an online discussion and material sharing space allocated to the instructor for instructional purpose. Her students had free access to these online resources. In Jiang's revision processes, he modeled after the sample essays that Elif shared in order to find clues as to how he can best revise his thesis statement, improve his 


\section{Masakazu Mishima}

presentation of evidence by correctly using APA in-text citations.

\section{Excerpt \#8}

Researcher : I can see you revised your thesis statement and in-text citations here. How did you do this?

Jiang : I did it because Elif said I need to change it.

Researcher : Did you use anything to make the changes?

Jiang : I looked at Elif's feedback but it doesn't tell me how to do it but I know there is a problem. My friends told me about sample essays so I looked at them.

Researcher : What sample essays? The ones your friend told you about?

Jiang : I can get them online-Blackboard. Elif uploaded them.

Researcher : Did you know about them before your friends told you?

Jiang $\quad$ : I did but I didn't think they were important.

Researcher : You read them all when you revised your essay?

Jiang : Not all of them. I just looked at thesis statement and how to show evidence.

Researcher : When you say, evidence, do you mean like APA?

Jiang : Yeah.

Researcher : Is it hard to learn APA in-text citations?

Jiang : No, it's easy. It's like math. I just need to know the rules.

The modeling strategy emerged out of the interaction with his peers. Before the interaction, despite the fact that the materials had been available from the beginning of the assignment, he was not aware of or did not pay attention to their relevancy to his writing/revision activity. However, the peer support strategy provided a ground for him to recognize the materials to use them as a means to scaffold his revision activity. For any form of affordance to mediate the agent's activity, he/she first has to perceive its relevancy to the activity. Hence, the emergence of the modeling strategy as used by Jiang in this particular instance showcases that the previous strategy use - the peer support strategy-may have generated a perceptual condition for the emergence of another strategy.

Another important point to be noted is that Jiang's modeling strategy was exclusively used for attending to the select issues-thesis statement and APA in-text citations. This is also true to his peer support strategy. Hence, as he reported, he decided to look at the only parts of the sample essays that were relevant to solving the specific writing problems. Again, this particular focus is evident in the peer support strategy. Jiang's selective attention to those issues and the ways in which he utilized the sample and classmates' essays were clearly reflective of his desire to meet the instructor's expectations in order to strengthen his alignment with the instructor who repeatedly mentioned or else provided written comments on Jiang's specific writing issues-thesis statement and evidence.

\section{Strategy to confirm alignment with the instructor's expectations}

Prior to the submission of his second draft, Jiang brought his essay to the other instructor who was teaching a section of the same course. In Elif's class, it was a customary practice for her to provide a tentative grade on students' second drafts to show their standings so as to encourage them to finalize their drafts with careful attention. As Jiang was fully aware of this practice, and also he was gravely concerned about his potential grade for his argumentative essay, he decided to ask for an opinion from another instructor on the quality of his essay. By this time, his second draft had been ready for submission, but he was unsure that the changes he had made to the draft would suffice most particularly in relation to the issues of argumentation and supporting evidence. Be reminded that Jiang received only indirect feedback on those types of issues:

\section{Excerpt \#9}

Researcher : What do you think about Elif's feedback on your argument and evidence? She wrote these comments like here [pointing at Elif's comments on the first page of Jiang's first draft].

Jiang : I really don't know what the instructor means and wants.

Researcher : Was it like that in China?

Jiang : No. Actually, I brought my [second] draft to the other instructor who teaches the same course, and the instructor said, "just a little change and you can get an A," but I don't get an A, and I wonder why. [Note: Shortly before this interview, Jiang received a $\mathrm{C}$ as a tentative grade on his second draft].

Researcher : But you did make some changes in your second draft.

Jiang : : I just did what I can but I don't know what's right or wrong. 
As shown in the excerpt above, the second opinion strategy was used to confirm if his revisions would meet Elif's expectations. What is interesting here is that he in fact did not know what was "right" or "wrong." It suggests that his overall strategy use including the second opinion strategy above was not used based on his understanding of what the problems actually were but rather to enact the kind of change that Elif would like to see in his paper.

One important tenet of the ecological approach is its view on learning as emergent and environmentally situated behavior (van Lier, 2004). As such, the following discusses the results of the present research by tethering the key conceptual tools adopted-agency, alignment, and affordance - to the notion of emergence. Thereby, it offers an extended interpretation of the results in an attempt to explain how one L2 writer's socio-materially afforded revision strategies emerged as a result of dynamic interplay of his agency and alignment with the environment.

\section{Agency as a historical antecedent to writing at the moment}

Jiang's revision strategy use was tightly connected to his agency - the desire to meet the instructor's expectations in order to achieve his goal - to receive a good grade. Jiang seemed to have held a strong belief that, in order to receive a good grade, faithfully following the instructor's directions was of paramount importance. As several researchers claimed that writing is a historically situated activity (e.g., Leki, 1995; Prior, 1998), Jiang's specific belief appeared to have been a carry-over from his past successful learning experience in China and preordained the way in which he engaged with the instructor's feedback and employed several revision strategies. The finding is comparable to Bhowmik (2016) which reported the participants actively used their past writing experiences to facilitate the completion of the writing task at hand. Leki (1995) also reported a similar finding that her participants' writing strategy use closely mirrored their past successful writing experiences.

What is distinctive in Jiang's case, however, is that his agency manifested as the strong desire to align with the instructor not so much as the task requirements as specified in the assignment sheet. The finding is contrastive to Bhowmik (2016) who found his participants' agency was geared toward the successful completion of the writing task by paying focused attention to the task requirements.

\section{Agency and the role of feedback}

The role of instructor feedback in Jiang's revision process was significant as it was the best conduit to understand the instructor's mental representation of good writing for the given assignment; whether it was provided in written or oral form, it seems to have served as a guiding map in order for Jiang to reach his destination. Jiang's attentiveness to Elif's feedback was evident in two of his revision strategies - the head-to-toe approach and retyping strategy - which he devised to conduct a thorough review of instructor's written comments and revise his draft accordingly. An additional example was his second opinion strategy. After revising his first draft, he brought his revised draft to another instructor of the same course to assess if his revision was sufficient to receive a good grade. All these strategies above were intimately associated with his agency-to receive a good grade and in order to achieve this personal goal, he assumed that thoroughly attending to instructor feedback was the best course of action.

\section{Agency and alignment with the environment}

The presence of social and/or material resources in the immediate environment was inseparably linked to all of his revision strategies. This is comparable to the findings reported by Lei (2008) and Bhowmik (2016). However, the study further offers an insight into how the writer selected his specific revision strategies. As mentioned earlier, Jiang used the head-to-toe approach to strengthen alignment with the instructor in order to satisfy his agentive need. The use of the strategy was materially afforded by a copy of the instructor commented essay draft and his laptop with which Jiang had established connection as priori-the presence and relevancy of these materials were perceived by Jiang before the use of the strategy. Without such connectivity to the material resources, this particular strategy use would not have been possible.

Likewise, Jiang's other strategies were all either socially or materially afforded but he aligned himself with these potential affordances before the enactment of his strategies. For instance, he had developed a social relationship with select classmates during the course of the semester. Then, Jiang sought help by consulting 
the select classmates whose grades were good and used their essays as samples to model after. Through the interaction with his peers, Jiang also found other materials to model after-the eight sample essays shared by the instructor. These two strategies were categorically similar in that Jiang ultimately used his peers' essays and sample essays as examples in revising his thesis statement and evidence. However, the use of the instructor-uploaded sample essays was clearly demonstrative of its generative nature owing to his earlier interaction with his peers; Jiang began utilizing the sample essays only after he had learned their relevancy from his classmates. Hence, his preexisting alignment with social/material resources warranted a possibility for his strategy use.

Another point which merits a reflection is the nature of Jiang's use of the two strategies above was foreshadowed by the difficulty in establishing alignment with the instructor. In particular, two specific writing issues-thesis statement and evidence-proved to be a challenge to Jiang since the instructor did not provide clear directions as to how the problems can be solved. His attention was selective in utilizing the strategies reflective of the said challenge presented by the two specific writing issues. While modeling is perhaps one of the most frequently reported strategies in the previous studies (e,g, Bhowmik, 2016; Lei, 2008, Leki, 1995; Hayes, 2012), most of the studies focused on explaining what strategy was used but not so much as how and/or why it was used. To this point, the findings of the current study contribute to the existing body of the literature.

\section{Emergence of revision strategies}

The brief overview of the findings above suggests that Jiang's revision strategies emerged as a result of dynamic interplay of his unique agency and connectivity to or alignment with the immediate ecosocial environment. In particular, Jiang's agency assumed a powerful mediating role in the way he engaged with instructor feedback and devised his revision strategies. Agency, as noted in the beginning of the paper, appears to give directions to the writer's overall revision activity, but also his revision activity was socially as well as physically situated and conditioned, which naturally becomes "emergent" as a result of the total interaction of any relevant elements - the learner, instructor feedback, peers, and possibly broader social/physical contextual settings (Ellis \& Larsen-Freeman, 2006, p. 558).

Since the physical and social conditions are destined to fluctuate and an individual's alignment with such conditions is also directed by his/her unique temporal agency, it is logical to assume that revision strategies may not be simply conceived as portable skills which can be carried across different writing contexts. Rather, even a similar strategy use reported in the previous studies such as modeling (Bhowmik, 2016; Lei, 2008, Leki, 1995; Hayes, 2012) may well be qualitatively different due to what environmental resources the writer aligns with and the nature of his/her agency. As such, a writer's strategy use and/or its outcome may not be strictly predictable even within one revision activity as Lantolf (2000) stated, "Activities, whether in the workplace, classrooms, or other settings, do not always unfold smoothly. What begins as one activity can reshape itself into another activity in the course of its unfolding" ( $p$. 11). Such strong connectivity between individual agency and his/her immediate ecosocial environment naturally leads to an ecologically bound revision activity in which the writer purposefully searches and utilizes potential mediating tools-whether it is social or physical - to adaptively coordinate the course of action in a given writing task. However, there seems to be a structural pattern - the nature of the writer's agency and alignment appear to shape how and why specific revision strategies may be employed. If so, future research may closely examine patterns of individual agency and of alignment with environmental resources. Such attempt can shed light on how individual differences/similarities in strategy use come into being in tight connection with the ecosocial environment and whether or not there is a systematic pattern exists across different writers in their strategy use.

\section{CONCLUSION}

Since the current research used a case study approach, a major limitation inherent is clearly its lack of generalizability. The interpretivist paradigm of research, however, takes a fundamentally different epistemological stance - the nature of knowledge claim rests on particularities and their relevance should be judged in relation to the context of potential audience-the reader. With that said, the significance of the study lies in its attempt to provide contextually rich accounts of an L2 
writer's revision activity within the naturalistic classroom environment. By using the ecological approach, the study offered an explanation of one L2 writer's revision process and his use of revision strategies in tight connection with the environment. Conceptualizing L2 writers' revision process as a situated and ecologically conditioned activity as demonstrated in the present research can be of significant value in understanding the complex nature of L2 writers' revision process. Further studies should be conducted to validate the findings and implications put forth in the preset research.

\section{REFERENCES}

Atkinson, D. (2005). Situated qualitative research and second language writing. In P. K. Matsuda \& T. Silva (Eds.), Second language writing research: Perspectives on the process of knowledge construction (pp. 49-64). New York: Routledge.

Atkinson, D. (2011). Alternative approaches to second language acquisition. New York: Routledge.

Atkinson, D., \& Sohn, J. (2013). Culture from the bottom up. TESOL Quarterly, 4, 669-693. doi: 10.1002/tesq.104.

Atkinson, D., Churchill, E., Nishino, T., \& Okada, H. (2007). Alignment and interaction in a sociocognitive approach to second language acquisition. The Modern Language Journal, 2, 169-188.

Bhowmik, K. S. (2016). Agency, identity and ideology in L2 writing: Insights from the EAP classroom. Writing \& Pedagogy, 2, 275-308. doi: 10.1558/wap.26864.

Bosher, S. (1998). The compositing processes of three South East Asian writers at the postsecondary level: An exploratory study. Journal of Second Language Writing, 7, 205-241. doi: 10.1016/s1060-3743(98)90013-3.

Brown, D. N. (2014). Agency and motivation to achieve language-learning objectives among learners in an academic environment in France. Journal of Applied Language Studies, 1, 101-126.

Casanave, C. P. (2003). Looking ahead to more sociopolitically-oriented case study research in L2 writing scholarship (But should it be called 'post process'?). Journal of Second Language Writing, 12, 85-102. doi:10.1016/S10603743(03)00002-X.

Conrad, S. M., \& Goldstein, L. M. (1999). ESL student revision after teacher-written-comments: Texts, contexts, and individuals. Journal of Second Language Writing, 8, 147-180. doi: 10.1016/s1060-3743(99)80126-x.

Costa, A., Pickering, M. J., \& Sorace, A. (2008). Alignment in second language dialogue. Language and Cognitive Processes, 4, 528-556. doi: 10.1080/01690960801920545.
De Guerrero, M. C. M., \& Villamil, S. O. (1994). Social-cognitive dimensions of interaction in L2 peer revision. The Modern Language Journal, 4, 484-496. doi: 10.1111/j.15404781.1994.tb02065.x.

Duff, P. (2012). Identity, agency, and SLA. In A. Mackey and S. Gass (Eds.)., Handbook of second language acquisition (pp. 410-426). London: Routledge.

Ellis, N. C., \& Larsen-Freeman, D. (2006). Language emergence: Implications for Applied Linguistics. Introduction to the Special Issue. Applied Linguistics, 27, 558-589. doi :10.1093/applin/aml02.

Ferris, D. R. (1997). The influence of teacher commentary on student revision. TESOL Quarterly, 31, 315-339. doi:10.2307/3588049.

Garrod, S., \& Pickering, J. M. (2009). Joint action, interactive alignment, and dialog. TOPICS, 2, 292-304.

Gee, J. P. (2004). Situated language and learning: A critique of traditional schooling. London: Routledge.

Gibson, J. E. (1982). The concept of affordances in development: The renascence of functionalism. In W. A. Collins (Ed.), The concept of development: The Minnesota symposia on child psychology: Vol. 15 (pp. 55-82). New York: Psychology Press.

Gibson, J. E., \& Pick, D. A. (2000). An ecological approach to perceptual learning and development. New York: Oxford University Press.

Gibson, J. J. (1979). The ecological approach to visual perception. Hillsdale, NJ. Erlbaum.

Glaser, B. G. (1978). Theoretical sensitivity: Advances in the methodology of grounded theory. Mill Valley, CA: Sociology Press.

Gold, L. R. (1958). Roles in sociological field observations. Social Forces, 3, 217-223.

Han, Y., \& Hyland, F. (2016). Oral corrective feedback on L2 writing from a sociocultural perspective: A case study on two writing conferences in a Chinese university. Writing \& Pedagogy, 3, 433-459.

Hayes, J. R. (2012). Modeling and remodeling writing. Written Communication, 3, 369-388. doi: 10.1177/0741088312451260.

Hedgcock, J., \& Lefkowitz, N. (1992). Collaborative oral/aural revision in foreign language writing instruction. Journal of Second Language Writing, 4, 51-70. doi: 10.1016/1060-3743(92)90006-b.

Hyland, F. (1998). The impact of teacher-written feedback on individual writers. Journal of Second Language Writing, 7, 255-286. doi: 10.1016/s1060-3743(98)90017-0.

Hyland, K., \& Hyland, F. (Eds.). (2006). Feedback in second language writing: Contexts and issues. Cambridge: Cambridge University Press. 
Kinginger, C. (2004). Alice doesn't live here anymore: Foreign language learning and identity reconstruction. In A. Pavlenko \& A. Blackledge (Eds.), Negotiation of identities in multilingual contexts (pp. 219-242). New York: Multilingual Matters.

Kramsch, C. (Ed.). (2002). Language acquisition and language socialization. London: Continuum.

Lantolf, P. J. (2000). Sociocultural theory and second language learning. Oxford: Oxford University Press.

Lantolf, P. J., \& Pavlenko, A. (2001). Second language activity theory: Understanding second language learners as people. In M. P. Breen (Ed.), Learner contributions to language learning (pp. 141-158). Harlow: Pearson Education.

Leather, J., \& van Dam, J. (Eds.). (2003). Ecology of language acquisition. Dordrecht: Kluwer Academic Publishers.

Lee, I. (2008). Student reactions to teacher feedback in two Hong Kong secondary classrooms. Journal of Second Language Writing, 17, 144164. doi: 10.1016/j.jslw.2007.12.001.

Lei, X. (2008). Exploring a sociocultural approach to writing strategy research: Mediated actions in writing activities. Journal of Second Language Writing, 17, 217-236.

Leki, I. (1995). Coping strategies of ESL writing students in writing tasks across the curriculum. TESOL Quarterly, 29, 235-260. doi: $10.2307 / 3587624$.

Leki, I., Cumming, A., \& Silva, T. (2008). A synthesis of research on second language writing in English. New York: Routledge.

Lyotard, J. F. (1984). The postmodern condition: A report on knowledge. Minneapolis: University of Minnesota Press.

Manchon, R.M., Roca de Larios, J., \& Murphy, L. (2007). A review of writing strategies. Focus on conceptualizations and impact of first language. In A. Cohen \& E. Macaro (Eds.), Language Learner Strategies: 30 years of research and practice (pp. 229-250). Oxford: Oxford University Press.

Nishino, T., \& Atkinson, D. (2015). Second language writing as sociocognitive alignment. Journal of Second Language Writing, 27, 37-54. doi:10.1016/j.jslw.2014.11.002.

Norton, B., \& Toohey, K. (2011). Identity, language learning, and social change. Language Teaching, 4, 412-446. doi: 10.1017/S0261444811000309.

Oxford, R. (1990). Language learning strategies: What every teacher should know. New York: Newbury House/Harper \& Row.

Pavlenko, A., \& Lantolf, P. J. (2000). Second language learning as participation and the (re)construction of selves. In J. P. Lantolf (Ed.), Sociocultural theory and second language learning (pp. 155-178). New York: Oxford University Press.
Prior, P. (1998). Writing/disciplinarity: A sociohistoric account of literate activity in the academy. Mahwah, NJ: Lawrence Erlbaum Associates.

Raimes, A. (1985). What unskilled writers do as they write: A classroom study of composing. TESOL Quarterly, 19, 229-258. doi: 10.1016/s10603743(97)90006-0.

Raimes, A. (1987). Language proficiency, writing ability, and composing strategies: A study of ESL college student writers. Language Learning, 37, 439-468. doi: 10.2307/3586828.

Reid, J. (2001). Advanced EAP writing and curriculum design: What do we need to know? In T. Silva, \& P. K. Matsuda (Eds.), On second language writing (pp. 143-160).

Roca de Larios, J., Murphy, L., \& Manchon, R. (1999). The use of restructuring strategies in EFL writing: A study of Spanish learners of English as a foreign language. Journal of Second Language Writing, 8, 13-44. doi: 10.1016/s10603743(97)90030-8.

Sasaki, M. (2000). Toward an empirical model of EFL writing processes: An exploratory study. Journal of Second Language Writing, 9, 259-291. doi: 10.1016/s1060-3743(00)00028-x.

Sasaki, M. (2002). Building an empirically-based model of EFL learners' writing processes. New Directions for Research in L2 Writing Studies in Writing, 11, 49-80. doi: 10.1007/978-94-0100363-6_3.

Seow, A. (2002). The writing process and process writing. In J. C. Richards \& W. A. Renandya (Eds.), Methodology in language teaching: An anthology of current practice (pp. 315-320). New York: Cambridge University Press.

Silva, T. (1990). Second language composition instruction: Developments, issues, and directions in ESL. In B. Kroll (Ed.), Second language writing: Research insights for the classroom (pp.11-23). Oxford: Oxford University Press.

Sze, C. (2002). A case study of the revision process of a reluctant ESL student writer. TESL Canada Journal, 19, 21-36. doi: 10.18806/tesl.v19i2.927.

Takagaki, T. (2003). The revision patterns and intentions in L1 and L2 by Japanese writers: A case study. TESL Canada Journal, 21, 22-38. doi: 10.18806/tesl.v21i1.272.

van Lier, L. (2000). From input to affordance: Socialinteractive learning from an ecological perspective. In J.P. Lantolf (Ed.), Sociocultural theory and second language learning (pp. 245259). Oxford: Oxford University Press.

van Lier, L. (2004). The ecology and semiotics of language learning: A sociocultural perspective. Boston, MA: Kluwer.

van Lier, L. (2008). Agency in the Classroom. In J. P. Lantolf \& M. E. Poehner (Eds.), Sociocultural Theory and the Teaching of Second Languages (pp. 163-186). London: Equinox. 
ENGLISH REVIEW: Journal of English Education

Volume 7, Issue 2, June 2019

van Lier, L. (2010). The ecology of language learning: Practice to theory, theory to practice. Procedia Social and Behavioral Sciences, 3, 2-6. doi: 10.1016/j.sbspro.2010.07.005.

Wang, C., \& Wang, M. (2014). Effect of alignment on L2 written production. Applied Linguistics, 1, $1-25$.

Wenden, A. L., \& Rubin, J. (Eds.). (1987). Learner strategies in language learning. UK: Prentice Hall.

Wong, A. T. Y. (2005). Writers' mental representations of the intended audience and of the rhetorical purpose for writing and the strategies that they employed when they
p-ISSN 2301-7554, e-ISSN 2541-3643 https://journal.uniku.ac.id/index.php/ERJEE

composed. System, 33, 29-47. doi: 10.1016/j.system.2004.06.009.

Yasuda, S. (2004). Revising strategies in ESL academic writing: A case study of Japanese postgraduate student writers. Journal of Asian Pacific Communication, 14, 91-112. doi: 10.1075/japc.14.1.07yas.

Yasuda, S. (2005). Different activities in the same task: Activity theory approach to ESL writing process. JALT Journal, 2, 139-168.

Yin, R. (2014). Case study research design and methods ( $5^{\text {th }}$ ed.). Thousand Oaks: Sage.

Zamel, V. (1983). The composing processes of advanced ESL students: Six case studies. TESOL Quarterly, 2, 165-188. 
Masakazu Mishima

Re-conceptualizing L2 writing revision strategies from an ecological perspective: An interview based inquiry 